\title{
Clinical study of botulinum toxin A injection combined with spasmodic muscle therapeutic instrument on lower limb spasticity in patients with stroke
}

\author{
XUDONG DING $^{1 *}$, LI HUANG $^{1 *}$, QINGSONG WANG $^{1}$, YANPING LIU $^{1}$, \\ JING ZHONG $^{2}$ and HUAXIAN CHEN ${ }^{1}$ \\ Departments of ${ }^{1}$ Rehabilitation Medicine and ${ }^{2}$ Ultrasound Imaging, Xiangyang No. 1 People's Hospital, \\ Hubei University of Medicine, Xiangyang, Hubei 441000, P.R. China
}

Received July 19, 2016; Accepted March 15, 2017

DOI: $10.3892 /$ etm.2017.4376

\begin{abstract}
The clinical effect of botulinum toxin A (BTX-A) injection combined with spasmodic muscle therapeutic instrument with simple BTX-A injection was compared. Eighty patients with stroke were randomly divided into the treatment and control groups of 41 and 39 cases, respectively. The two groups of patients were given routine rehabilitation therapy. Ultrasound-guide positioning technology was used; treatment group was administered BTX-A injection combined spasmodic muscle therapeutic instrument while the control group received only BTX-A injection. Muscle tension and motor function were evaluated at 1, 4,8 and 12 weeks after treatments by rehabilitation physician who was not aware of the grouping of the patients. Muscle tension was significantly reduced after BTX-A injection in the treatment and control groups. Modified Ashworth scale scores of the treatment and control groups 1 and 4 weeks after treatment were significantly lower than those before treatment. Motor function of lower limbs of patients, 1 and 4 weeks after treatment improved significantly. The comparison of step size and walking speed of the groups showed obvious differences with statistical significance $(\mathrm{P}<0.01)$. In conclusion, ultrasonic guidance BTX-A injection is easy to operate with good safety. It can effectively improve extensor myospasm of lower limb of patients with rapid onset and the spasm relief can last for three months. Spasmodic muscle therapeutic instrument can improve the spasm condition of lower limb muscle after stroke as well as motor function
\end{abstract}

Correspondence to: Dr Huaxian Chen, Department of Rehabilitation Medicine, Xiangyang No. 1 People's Hospital, Hubei University of Medicine, 15 Jiefang Road, Xiangyang, Hubei 441000, P.R. China

E-mail: chen_huaxian1@163.com

${ }^{*}$ Contributed equally

Key words: botulinum toxin A, spasmodic muscle therapeutic instrument, stroke, lower limb spasticity of lower limbs and activity of daily living, which can make spasmolysis of BTX-A last for a longer period of time.

\section{Introduction}

Stroke is a common, frequently-occurring geriatric disease. Approximately, $75 \%$ of survivors have disabilities to varying degrees, especially spastic hemiplegia, with the morbidity rate reaching $80 \%$ (1). Affected groups of muscle have no force to oppose constriction caused by spastic dystonia which leads to abnormal limb postures. There are many therapeutic methods for myospasm, mainly including removal of inducement, physical therapy (for instance, kinesiotherapy and electric stimulation therapy), acupuncture, oral medication, nerve block and operation (for instance, high selective posterior rhizotomy) (2-5). The effects of oral drug therapeutics are satisfactory, but have certain adverse side effects. Local injection of carbolic acid may lead to dysfunction of walking and standing and abnormal painful sensation may occur. The acupuncture and moxibustion therapy of traditional Chinese medicine is also one of the methods used to treat spasticity of extremities in stroke hemiplegia, but the effects of therapeutic is still lacking clinical research support of exact and large number of samples. Operative treatment has more serious trauma and complications, which needs to strictly grasp indications and contraindications. As an exotoxin generated by clostridium botulinum in anaerobic environment, botulinum toxin A (BTX-A) acts on the neuromuscular junction of cholinergic motor nerve ending where it inhibits the release of acetylcholine (ACh) mediated by calcium ions, leading to the decrease of muscular tension and relieves myospasm (6-9). In recent years, local injection of BTX-A has been used to treat myospasm and myotonia after stroke and brain injury (7,10-13). This method had significant therapeutic effects, less adverse reaction, user simplicity and no need of anesthesia, with great superiority.

The therapeutic effects of the injection of BTX-A are closely related to the accurate localization of the muscle. At present, the common methods of localization consist of bare-handed touching, method of electrical stimulation localization, method of multichannel electromyography localization 
and the method of ultrasonic guidance localization (14-16), among which, the method of ultrasonic guidance muscle localization has attracted increased attention. Ultrasound can be used to directly observe the morphological characteristics of target muscles, especially deep layer target muscle that is difficult to be touched by hand. The application of ultrasonic guidance technology can improve the accuracy of injection and accurately penetrate needle into target muscle (especially deep layer target muscle) to relieve patients' suffering. Since the ultrasound of high frequency probe can clearly show the nerves and blood vessels around target muscle, the application of ultrasonic guidance technology can also avoid injuries to adjacent blood vessels and nerves $(17,18)$.

As a physical therapeutic means, the spasmodic muscle therapeutic instrument uses an interactive inhibition principle to generate alternant stimulation for spasmodic muscle and antagonistic muscle, relax spasmodic muscle and improve muscle strength of antagonistic muscle by alternatively outputting two groups of pulses with low frequency, thereby coordinating the active muscle group and antagonistic muscle group, improving limb movement. Studies showed that the pulse of low frequency electric stimulation for spasmodic muscle could lower muscular tension and most patients were reported to have spasm relieved within 6-14 h after treatment $(19,20)$.

The present study applied ultrasonic guidance localization technology to compare the spasmolysis effects between treatment by combining BTX-A injection and spasmodic muscle therapeutic instrument and treatment by only BTX-A injection and analyzed the spasmolysis effects and the effects on motor function of BTX-A, as well as whether spasmodic muscle therapeutic instrument had coordination effects, through treatments of local injection of BTX-A and spasmodic muscle therapeutic instrument for patients with lower limb myospasm after stroke.

\section{Patients and methods}

Research subjects. Eighty cases of patients with stroke hospitalized in the Department of Neurology of Xiangyang No. 1 People's Hospital from December 2013 to December 2014 were enrolled, of whom, 41 were male and 39 were female. The diagnosis conformed to the diagnosis criteria of 'Cerebrovascular Disease Classification' formulated at the 4th Chinese Conference of Cerebrovascular Disease in 1995 (21). This study was approved by the Ethics Committee of Xiangyang No. 1 People's Hospital. Signed written informed consents were obtained from all participants before the study.

Inclusion criteria. The inclusion criteria were: i) Initial onset, unilateral lesion that was diagnosed by computed tomography (CT) or magnetic resonance imaging (MRI); ii) the course of disease was 3-6 months, aged $\leq 70$ years; iii) without severe cognitive dysfunction (Mini-Mental State Examination, MMSE; 224), patients who understood and cooperated with treatment; iv) without injecting botulinum toxin in the prior 2 weeks or the effect of other anti-vasospasm drugs was not obvious; v) with partial body paralysis, modified Ashworth scale (MAS) score of lower limb local muscle spasm $\geq 2$; and vi) vital signs were stable, without other severe liver disease and history of epilepsy.
Exclusion criteria. The exclusion criteria were: i) Subarachnoid hemorrhage; ii) patients with multiple cerebral infarction or cerebral hemorrhage; iii) lower limb joint contracture; iv) combined with severe heart, liver, kidney disease and infection; v) patients who took drugs which aggravated neuromuscular junction transmission dysfunction (such as quinine, aminoglycoside antibiotics and morphine); vi) target limb of patients with nerve injury or who underwent operational treatment (such as nerve block); and vii) patients with infection at injection site.

Instruments and drugs. The following instruments and drugs were used: i) Color Doppler ultrasonic diagnostic apparatus, (GE Healthcare; Princeton, NJ, USA); instrument model: Logiq 9; probe model: M12L (frequency, 9-12 MHz). ii) Muscle spasm treatment instrument, (Anyang Xiangyu Medical Equipment Co., Ltd., Henan, China); instrument model: XY-K-JLJ-3D; iii) BTX-A for injection. Commodity name: Heng Li; specification: $100 \mathrm{U}$ (China Lanzhou Institute of Biological Products, Lanzhou, China; iv) sterile medical gloves and disposable gloves; v) normal saline; vi) anerdian and medical cotton swab and vii) ultrasonic coupling agent.

Study methods. Eighty cases of patients with stroke that conformed to the criteria, were randomly divided into the treatment group (41 cases) and the control group (39 cases), and patients in the two groups were given routine recovery treatment. Patients in the treatment group were administered BTX-A injection and spasmodic muscle therapeutic instrument treatment, while patients in the control group were only given BTX-A injection. Muscle tension and motor function of patients in both groups before treatment and at 1, 4, 8 and 12 weeks after receiving treatment were evaluated by rehabilitation physician blinded to the patients grouping.

\section{$B T X-A$ injection treatment \\ Injection treatment of $B T X-A$.}

Preparation of botulinum toxin. BTX-A was stored at $4^{\circ} \mathrm{C}$. Normal saline $(4 \mu \mathrm{l})$ was used to dilute $100 \mathrm{U}$ BTX-A to reach $25 \mathrm{U} / 1 \mathrm{ml}$. BTX-A was used immediately after it was ready and the rest of the solution was discarded.

Ultrasonic guidance localization injection. The operation was conducted in an ultrasonography room. Patients lay in a supine position or prostrate and the patient's skin was disinfected with iodophor. The ultrasonic probe was stainedwith appropriate coupling agent, entangled with sterile gum cover and placed at the marked positions of target muscle to be injected. The direction of the probe was perpendicular to the long axis of lower limb, to confirm the position and the range of target muscle through ultrasonography (if necessary, the target muscle was stretched to further confirm the changes of its dynamic constriction) and to clearly display muscle by adjusting the depth and other parameters of ultrasonic apparatus. Tibialis posterior, gastrocnemius muscle and soleus were selected as injection points according to the malformation manifestation of patients. The prepared BTX-A solution was taken to be accurately injected into different target muscles, respectively, under ultrasonic guidance, and attention was paid to avoid blood vessels and nerves. Patient's vital signs, allergy and other adverse reactions were strictly observed. 
Table I. Injection parts and doses.

\begin{tabular}{ccc}
\hline $\begin{array}{c}\text { Dose }(\mathrm{U}), \\
\text { constant } \\
\text { force }\end{array}$ & $\begin{array}{c}\text { Injection } \\
\text { points }\end{array}$ \\
\hline
\end{tabular}

Posterior muscular

group of leg

Gastrocnemius

$100 \quad 1-3$ points at the bump pad

muscle-medial head

of shallow muscle on the medial side of posterior surface leg

Gastrocnemius

muscle-lateral head

$100 \quad 1-3$ points at the bump pad of shallow muscle on the lateral side of posterior surface leg

Soleus

100

Needle was inserted at the distal end of muscle belly of gastrocnemius muscle and inside front of achilles tendon, 1-3 points

Tibialis posterior

50

Needle was inserted at 5 finger-breath at the distal end of tibial tubercle and 1 finger-breath at the medial side of tibia to skew through soleus and flexor digitorum longus, closely adhering to the rear of tibia. Needle could also be inserted in front of tibia and between $1 / 3$ tibia and fibula in the middle and inferior segment of shank to pass through tibialis anterior or extensor digitorum longus, with breakthrough feeling in case of passing through interosseous membrane in the front, then directly enter into tibialis posterior, 1-3 points
Each target muscle was injected at 3-5 points, with a total dose of 350 units. Single injection was applied generally. After injection, the patient was seated and told to avoid massage and scrubbing the injection parts within 6-24 h to prevent local diffusion of the drug (22). Table I shows the specific injection parts and injection doses.

Treatment by spasmodic muscle therapeutic instrument. i) Connection of power supply: The power line provided with the instrument was inserted into the outlet of the back panel of the instrument, then the power line plug was inserted into $220 \mathrm{~V}$ AC power supply (please note that the power supply outlet should have good ground wire). ii) Power switch was turned on. iii) Selection of built-in prescriptions: In case therapeutic instrument hinted that 'Path A electrodes are placed at tendons at both ends of spasmodic muscle and path B electrodes are placed at the muscle belly of its antagonist', with the buzzing sound, the instrument entered into the interface of built-in prescriptions and the prescription parameters were seen on the screen. iv) Fixation of electrodes: output of the two electrode slices from path A was placed at tendons at both ends of spasmodic muscle and the two electrode slices of path B were placed at both ends of the muscle belly of its antagonist (adjoining skin with flannelette surface). After electrodes were ensured to be in good contact with the skin, they could be fixed with a bandage. v) When starting, the 'on/off' button was pressed, therapeutic instrument showed the 'saved' at the lower right corner of interface, accompanied with buzzing, then entered into working state and displayed working interface. vi) Determination of output current intensity: In case of adjusting output current, it was required to continually ask the reactions of the patients, until the obvious contraction of the patient's muscle. Since the human body is rather sensitive to current at the beginning, the current needed fine adjustment within 1-2 min after being adjusted so as to try to increase output current. In case it was unbearable for patients, the appropriate key was used to decrease the output current. vii) End of treatment: The time was count during the therapeutic process. When the time showed 0, output stopped and the instrument was buzzing. viii) Treatment course: One treatment course was 10 days, with a total of three treatment courses.

\section{Assessment methods}

Assessment of muscle tension. The MAS (23) was applied to assess muscle tension of lower limbs of patients. The assessed muscles included tibialis posterior, gastrocnemius muscle and soleus.

Assessment of motor function of lower limbs. The simplified scale (Fugl-Meyer assessment, FMA) (24) was applied to assess motor function of lower limbs of patients. There were 50 minor items in the Fugl-Meyer motor scale. Each item was scored with 0,1 and 2 scores from low to high according to motor functions, of which there were 17 items for lower limbs, with a total of 34 scores. The higher the score is, the better the motor function is.

Assessment of activity of daily living. The modified Barthel index (MBI) (25) was applied to assess activity of daily living (ADL) (Table II).

Assessment of step size and walking speed. Patients were asked to walk $10 \mathrm{~m}$ and the average value of 3-step lengths in middle $6 \mathrm{~m}$ by using footprint measurement. The time of walking $10 \mathrm{~m}$ was recorded by stopwatch, thus to calculate walking speed.

Statistical analysis. SPSS 17.0 software (Chicago, IL, USA) was used for statistical analysis. Data were analysed by t-test. Experimental data are expressed as the mean \pm standard deviation (SD). Countable data were tested by Chi-square. $\mathrm{P}<0.05$ was considered to indicate a statistically significant difference.

\section{Results}

Comparison of general data of patients in the two groups. Eighty cases of patients were enrolled in this study, 41 cases 
Table II. MBI scale.

\begin{tabular}{|c|c|c|c|c|c|}
\hline ADL item & $\begin{array}{c}\text { Completely } \\
\text { dependent, level } 1\end{array}$ & $\begin{array}{c}\text { Maximum } \\
\text { help, level } 2\end{array}$ & $\begin{array}{c}\text { Moderate } \\
\text { help, level } 3\end{array}$ & $\begin{array}{c}\text { Minimum } \\
\text { help, level } 4\end{array}$ & $\begin{array}{c}\text { Completely } \\
\text { independent, level } 5\end{array}$ \\
\hline Modification & 0 & 1 & 3 & 4 & 5 \\
\hline Bath & 0 & 1 & 3 & 4 & 5 \\
\hline Feeding & 0 & 2 & 5 & 8 & 10 \\
\hline Toileting & 0 & 2 & 5 & 8 & 10 \\
\hline Dressing & 0 & 2 & 5 & 8 & 10 \\
\hline Defecating control & 0 & 2 & 5 & 8 & 10 \\
\hline Urinary control & 0 & 2 & 5 & 8 & 10 \\
\hline Up-down transfer & 0 & 2 & 5 & 8 & 10 \\
\hline Bed and chair transfer & 0 & 3 & 8 & 12 & 15 \\
\hline Walking on flat ground & 0 & 3 & 8 & 12 & 15 \\
\hline
\end{tabular}

The higher the scores of MBI scale are, the better the independence is. The scores $\geq 60$, mild dysfunction and basic self-care daily life; scores of 41-59, moderate dysfunction in need of help for daily life; scores of 21-40, severe dysfunction and obvious dependence in daily life; scores $\leq 20$, total disability and total dependence in daily life. MBI, modified Barthel index; ADL, activity of daily living.

Table III. Comparison of general data of patients in the two groups.

\begin{tabular}{lccc}
\hline Item & $\begin{array}{c}\text { Treatment } \\
\text { group }\end{array}$ & $\begin{array}{c}\text { Control } \\
\text { group }\end{array}$ & $\begin{array}{c}\text { Intergroup } \\
\text { P-value }\end{array}$ \\
\hline Cases & 41 & 39 & \\
Male & 21 & 20 & \\
Female & 20 & 19 & $>0.05$ \\
Cerebral infarction & 29 & 28 & \\
Cerebral hemorrhage & 12 & 11 & $>0.05$ \\
Diseased region & & & \\
Left site & 22 & 21 & $>0.05$ \\
Right site & 19 & 18 & $>0.05$ \\
Age (years) & $61.23 \pm 6.2$ & $62.52 \pm 7.1$ & $>0.05$ \\
Course of & $127.6 \pm 27.6$ & $125.5 \pm 31.3$ & \\
disease (day) & & & \\
\hline
\end{tabular}

were male and 39 were female; There were cerebral infarction in 57 cases, cerebral hemorrhage in 23 cases; the average age was $62.03 \pm 6.54$ years and average course of disease $126.7 \pm 29.72$ days. Basic data of the groups had no obvious difference through statistical processing $(\mathrm{P}>0.05)$ (Table III).

Comparison of MAS score of patients in the two groups before and after treatment. After the injection of BTX-A, muscle tension of the treatment and control groups decreased significantly, MAS scores of the treatment and control groups 1 and 4 weeks after treatment decreased significantly $(\mathrm{P}<0.01)$, compared with those before treatment. Antispasmodic effect 4 weeks after treatment was more obvious, and no obvious difference of MAS scores was found $(\mathrm{P}>0.05)$. MAS score of the control group 12 weeks after treatment significantly increased $(\mathrm{P}<0.05)$ compared with that before treatment. Muscle tension of the treatment group increased significantly $(\mathrm{P}<0.01)$, but more slowly compared with the control group. MAS score was statistically significant compared with that before treatment MAS score differences between the groups were statistically significant at this point $(\mathrm{P}<0.05)$ (Table IV).

Comparison of FMA score of patients in both groups before and after treatment. Compared with the treatment group, lower limb motor function improved significantly 1 and 4 weeks after treatment, the difference of FMA score of two groups was not statistically significant ( $P>0.05)$, the difference of FMA score of two groups was statistically significant 12 weeks after treatment $(\mathrm{P}<0.05)($ Table $\mathrm{V})$.

Comparison of MBI score of patients in both groups before and after treatment. Results showed that, MBI score 1 week after treatment compared with that before the treatment, the difference was not statistically significant, 4,8 and 12 weeks after treatment. Compared with that before treatment, MBI scores of both groups were significantly higher than those before treatment $(\mathrm{P}<0.05)$. However, compared with the control group, function of the treatment group 8 weeks after treatment improved more significantly $(\mathrm{P}<0.05)$ (Table VI).

Comparison of waking speed and step size of patients in two groups before and after treatment. The difference of waking speed and step size of the groups 1 and 4 weeks after treatment was not statistically significant $(\mathrm{P}>0.05)$, waking speed and step size, 8 and 12 weeks after treatment had obvious differences, which was statistically significant $(\mathrm{P}<0.01)$ (Tables VII and VIII).

\section{Discussion}

Therapeutic and antispasmotic effects of local injection of BTX-A on muscle spasticity after stroke. After stroke, due to upper motor neuron injury, the interactions between $\alpha$ - and $\gamma$-motor neurons was imbalanced with a domination of $\gamma$-motor neuron, which caused the reduced effects of the central motor 
Table IV. Comparison of MAS score of patients in the two groups before and after treatment (mean \pm SD).

\begin{tabular}{lccccc}
\hline Groups & $\begin{array}{c}\text { Before } \\
\text { treatment }\end{array}$ & $\begin{array}{c}\text { 1 week after } \\
\text { treatment }\end{array}$ & $\begin{array}{c}4 \text { weeks after } \\
\text { treatment }\end{array}$ & $\begin{array}{c}8 \text { weeks after } \\
\text { treatment }\end{array}$ & $\begin{array}{c}12 \text { weeks after } \\
\text { treatment }\end{array}$ \\
\hline Treatment & $4.19 \pm 0.57$ & $2.81 \pm 0.61$ & $1.36 \pm 0.73$ & $1.87 \pm 0.53$ & $2.26 \pm 0.58$ \\
Control & $4.01 \pm 0.52$ & $2.69 \pm 0.59$ & $1.33 \pm 0.65$ & $1.78 \pm 0.73$ & $2.88 \pm 0.60$ \\
P-value & $>0.05$ & $>0.05$ & $>0.05$ & $>0.05$ & $<0.05$ \\
\hline
\end{tabular}

MAS, modified Ashworth scale.

Table V. Comparison of FMA score of patients in the two groups before and after treatment (mean \pm SD).

\begin{tabular}{lccccc}
\hline Groups & $\begin{array}{c}\text { Before } \\
\text { treatment }\end{array}$ & $\begin{array}{c}\text { 1 week after } \\
\text { treatment }\end{array}$ & $\begin{array}{c}\text { 4 weeks after } \\
\text { treatment }\end{array}$ & $\begin{array}{c}8 \text { weeks after } \\
\text { treatment }\end{array}$ & $\begin{array}{c}12 \text { weeks after } \\
\text { treatment }\end{array}$ \\
\hline Treatment & $7.19 \pm 0.87$ & $8.51 \pm 0.69$ & $13.26 \pm 0.85$ & $18.87 \pm 0.53$ & $25.16 \pm 0.78$ \\
Control & $7.23 \pm 0.77$ & $8.62 \pm 0.58$ & $12.83 \pm 0.64$ & $19.48 \pm 0.71$ & $16.88 \pm 0.66$ \\
P-value & $>0.05$ & $>0.05$ & $>0.05$ & $>0.05$ & $<0.05$ \\
\hline
\end{tabular}

FMA, Fugl-Meyer assessment.

Table VI. Comparison of MBI score of patients in the two groups before and after treatment (mean \pm SD).

\begin{tabular}{lccccc}
\hline Groups & $\begin{array}{c}\text { Before } \\
\text { treatment }\end{array}$ & $\begin{array}{c}\text { 1 week after } \\
\text { treatment }\end{array}$ & $\begin{array}{c}4 \text { weeks after } \\
\text { treatment }\end{array}$ & $\begin{array}{c}8 \text { weeks after } \\
\text { treatment }\end{array}$ & $\begin{array}{c}12 \text { weeks after } \\
\text { treatment }\end{array}$ \\
\hline Treatment & $24.86 \pm 6.97$ & $27.54 \pm 7.29$ & $55.27 \pm 8.89$ & $68.85 \pm 7.43$ & $82.17 \pm 10.58$ \\
Control & $26.53 \pm 8.75$ & $28.62 \pm 8.59$ & $47.69 \pm 9.24$ & $56.92 \pm 8.71$ & $61.87 \pm 7.96$ \\
P-value & $>0.05$ & $>0.05$ & $>0.05$ & $<0.05$ & $<0.05$ \\
\hline
\end{tabular}

MBI, modified Barthel index.

Table VII. Comparison of waking speed (m/sec) of patients in the two groups before and after treatment (mean \pm SD).

\begin{tabular}{lccccc}
\hline Groups & $\begin{array}{c}\text { Before } \\
\text { treatment }\end{array}$ & $\begin{array}{c}\text { 1 week after } \\
\text { treatment }\end{array}$ & $\begin{array}{c}4 \text { weeks after } \\
\text { treatment }\end{array}$ & $\begin{array}{c}8 \text { weeks after } \\
\text { treatment }\end{array}$ & $\begin{array}{c}12 \text { weeks after } \\
\text { treatment }\end{array}$ \\
\hline Treatment & $0.36 \pm 0.20$ & $0.39 \pm 0.29$ & $0.41 \pm 0.28$ & $0.55 \pm 0.25$ & $0.62 \pm 0.28$ \\
Control & $0.36 \pm 0.26$ & $0.37 \pm 0.25$ & $0.39 \pm 0.26$ & $0.46 \pm 0.21$ & $0.45 \pm 0.27$ \\
P-value & $>0.05$ & $>0.05$ & $>0.05$ & $<0.01$ & $<0.01$ \\
\hline
\end{tabular}

Table VIII. Comparison of step size of patients in the two groups before and after treatment (mean \pm SD).

\begin{tabular}{lccccc}
\hline Groups & $\begin{array}{c}\text { Before } \\
\text { treatment }\end{array}$ & $\begin{array}{c}\text { 1 week after } \\
\text { treatment }\end{array}$ & $\begin{array}{c}\text { 4 weeks after } \\
\text { treatment }\end{array}$ & $\begin{array}{c}8 \text { weeks after } \\
\text { treatment }\end{array}$ & $\begin{array}{c}12 \text { weeks after } \\
\text { treatment }\end{array}$ \\
\hline Treatment & $0.38 \pm 0.26$ & $0.41 \pm 0.30$ & $0.47 \pm 0.31$ & $0.57 \pm 0.28$ & $0.64 \pm 0.32$ \\
Control & $0.39 \pm 0.25$ & $0.41 \pm 0.29$ & $0.46 \pm 0.30$ & $0.47 \pm 0.27$ & $0.46 \pm 0.21$ \\
P-value & $>0.05$ & $>0.05$ & $>0.05$ & $<0.01$ & $<0.01$ \\
\hline
\end{tabular}

inhibition system to release the original function of lower center. It also enhances the excitability of motor circuit and increase muscular tension of affected side limb leading to the occurrence of spasticity. It is expressed as the increased 
muscular tension of upper limb flexor group and lower limb extensor group (26).

At present, there is no safe and effective therapeutic method for muscle spasticity after stroke. Physiotherapy can temporarily reduce local muscular tension, but the long-term therapeutic effects remain uncertain (27). The therapeutic effects of oral drugs are not ideal and there are certain side effects in case of taking large doses. Surgical treatment has risks and its therapeutic effects do not last long. The treatment of intradural injection of baclofen is not applicable for local myospasm and is easy to spread to other parts of the brain with poor tolerance. After Das and Park (28) first applied botulinum toxin to treat secondary myotonia caused by the injury of central nervous system in 1989, many similar clinical studies occurred in succession and the therapeutic actions of botulinum toxin for myospasm and myotonia after stroke or brain injury were confirmed.

Botulinum toxin is a macromolecular protein toxin generated by anaerobic clostridium botulinum of fusiform bacilus. Botulinum toxin is divided into 7 types according to its immunology and serology, namely, A, B, C, D, E, F and G, among which BTX-A has stable toxicity and is easy to be produced, purified and refined, thus was the first applied in experimental studies and clinic (29). After the injection, BTX-A diffuses in local muscle, closely combines with cholinergic presynaptic receptor of nerve muscle junction, and inhibits the release of presynaptic membrane acetylcholine mediated by calcium ion, thus causing more durable muscle relaxation effect. This study showed that the myospasm of treatment group and control group was relieved significantly after BTX-A injection. The eighty treated patients witnessed effects one week after BTX-A injection and were aware of muscle relaxation and felt that their muscle softened when touching. The MAS scores of treatment group and control group within 1 and 4 weeks after treatment decreased remarkably $(\mathrm{P}<0.01)$ compared to those before treatment. Antispasmodic effects were more obvious 4 weeks after treatment, which was in line with the conclusion of relevant report that the effects of BTX-A on relieving myospasm reached the peak about one month after injection (30-33).

The therapeutic effects of BTX-A injection are closely related to the accurate localization of the muscle (34). To obtain the best therapeutic effects, it is required to carefully select injection muscle and its injection point. According to literature, the current methods of localization used consisted of bare-handed touching, multichannel electromyography, electrical stimulation, ultrasonic wave and CT (14-18) and each method of localization had its own strengths. As a new technology for the localization of muscle, ultrasound guided localization has increasingly extensive clinical application due to its advantages, such as non-invasion, high resolution ratio and easy operation. Our study showed that the application of color Doppler ultrasonography could fully meet the requirements of localization. Under ultrasound, muscle was characterized by low echo, tendon was characterized by tubular high-echo lines (threadiness), and muscle fascia was characterized by high echo. Equipped with high frequency probe, target muscle and its surrounding nerve and blood vessels were clearly visible. Guided by ultrasound, the operator could not only reach target muscle, especially deep and the smaller muscles, but avoided surrounding nerves and blood vessels.
Duration of therapeutic effects of myospasm after stroke treated by BTX-A. BTX-A leads to corresponding muscle relaxation of paralysis through inhibiting acetylcholine released by presynaptic membrane of nerve muscle junction. This process is divided into three stages:

i) Combination stage: With cholinergic specificity, the heavy chain of BTX-A can rapidly combine with the specific receptor on the surface of peripheral nerve cell and this process is reversible.

ii) Localization stage: BTX-A enters into cell membrane through pinocytosis.

iii) Paralysis stage: The light chain of BTX-A is zinc endopeptidase and inhibits the release of presynaptic membrane acetylcholine mediated by calcium ion through hydrolyzing relevant protein of zinc-dependent synapse, thus leading to muscle relaxation through this chemical denervation mechanism $(6,35)$.

Since BTX-A has no destructive effect on presynaptic membrane, the effects of muscle relaxation of this chemical denervation mechanism can last for 3-6 months in general, and then myospasm may relapse with the function regeneration of new nerve endings and motor end plates, as well as the gradual recovery of nerve conduction and muscular activity (36-38). The duration of therapeutic effects of BTX-A injection is not always the same. Hesse et al reported that the therapeutic effects of half of patients only lasted for 2 months (39), while Pullman et al proved in his study that the therapeutic effects of several patients exceeded one year (40).

In our study, MAS scores of both control and treatment groups increased 12 weeks after treatment, but the differences still had statistical significance $(\mathrm{P}<0.05)$ by comparing with those before treatment. Moreover, the results also showed that MAS scores of control group increased more steeply than those of treatment group, and at that point, the differences of MAS scores between two groups had statistical significance $(\mathrm{P}<0.05)$. These results suggested that the myospasm degree of control group had an upward trend 12 weeks after injection and the antispasmodic effects of treatment group also increased slightly, but more gently than that of control group. In our study, the duration of therapeutic effects of BTX-A injection lasted for more than 3 months, but exact duration of therapeutic effects need to be confirmed by longer observation and follow-up. Moreover, we analyzed that the duration of therapeutic effects was also related to factors, such as the course of disease, size of target muscle, injection dose and combination with other treatment, including rehabilitation therapy.

Comparison of motor function of patients in both groups before and after treatment. BTX-A has been proved to be an effective anticonvulsant. Its principle action was that it inhibited the irritant and spontaneous release of acetylcholine mediated by calcium ion through acting on presynaptic membrane of motor end plate. Without blocking the conduction of nerve excitability, it had no harmful effect on the conductivity and excitability for nerves and muscles and it was reversible and local dominating effect of chemical denervation. Although BTX-A injection had the advantages of rapid onset spasmolysis, strong selectivity and few adverse reactions, improvement of single spasm could not be directly 
reflected as the improvement of functions of body exercise. Studies showed that no effects of BTX-A on the ADL had been observed after BTX-A injection, such as functional independence measurement (41) and Barthel index (27). For stroke patients, the decrease of muscular tension was only one of rehabilitation goals and the improvement of ADL was equally important. Relevant studies were conducted to improve the therapeutic effects of BTX-A injection. Frasson et al (42) injected BTX-A for stroke patients with myospasm, respectively stimulated the muscle with 4 and $25 \mathrm{~Hz}$ for $30 \mathrm{~min} /$ day for 5 consecutive days. The observation of the effects on the spasmolysis of BTX-A showed that short-time electric stimulation at low frequency of $4 \mathrm{~Hz}$ could bring faster and more durable antispasmodic effects of BTX-A.

The treatment group in the study was conducted with BTX-A injection, combined with spasmodic muscle therapeutic instrument. The most important character of spasmodic muscle therapeutic instrument was to alternately emit two groups of pulses with adjustable wave width and frequency, conduct alternant stimulation for spasmodic muscle and antagonistic muscle through $\mathrm{A}$ and $\mathrm{B}$ pathways with the delay time of 0.1-1.5 sec, relax spasmodic muscle through reciprocal inhibition, improve muscle strength of antagonistic muscle and effectively reduce muscular tension. Moreover, the alternant stimulation for spasmodic muscle and antagonistic muscle could conduct excitement to center and was of benefit to adjust various kinds of reflections, thus to coordinate active muscles and antagonistic muscles to overcome the abnormal pattern of limbs after hemiplegia (43). Findings showed that low frequency pulse electric stimulation for spasmodic muscle could lower muscular tension and most patients were reported to have spasm relieved within 6-14 h after each treatment (44).

Our study applied FMA, MBI, step size and walking speed respectively to evaluate the motor functions of lower limb, ADL and walking function. The results showed that the motor functions of lower limb of patients 1 and 4 weeks after treatment significantly improved by comparing with those before treatment and FMA scores had no significant differences between the groups $(\mathrm{P}>0.05)$. FMA scores had significant differences between the groups 12 weeks after treatment. MBI scores of patients in both groups 4,8 and 12 weeks after treatment were significantly higher than those before treatment $(\mathrm{P}<0.05)$. However, compared with control group, the improvement of function in treatment group was more significant 8 weeks after treatment; both step size and walking speed of the groups had significant differences 8 and 12 weeks after treatment. Thus, BTX-A injection rapidly, effectively and continuously reduced muscular tension, improved spasticity and created good conditions for limb rehabilitation. In the case of combining with other treatments, it accelerated the recovery process of ADL of patients and made therapeutic effects last to 12 weeks after treatment. Based on the effects of function improvement of treatment and control group, FMA scores, the measured values of step size and walking speed between both groups had no significant differences or statistical significance 1 and 4 weeks after treatment, but the differences of FMA scores, the measured values of step size and walking speed between the groups had statistical significance 8 and 12 weeks after treatment. Lower limb functions of treatment had more significant improvement, which showed that spasmodic muscle therapeutic instrument had synergistic effects in the combined application of treating myospasm with botulinum toxin.

In conclusion, BTX-A injection guided by ultrasound was simple to operate and had good safety. It could effectively improve lower limb extensor muscle spasm of stroke patient with rapid onset effect, and could relieve spasm for 3 months. Spasmotic muscle therapeutic instrument could improve the situation of lower limb myospasm after stroke as well as motor functions of lower limb and ADL, and make spasmolysis of BTX-A more durable. In clinical practices, we should grasp any opportunity provided by spasmolysis after BTX-A injection, it actively shorten the course of treatment by combining with other means of rehabilitation therapy and promoted function recovery.

\section{References}

1. Lloyd-Jones D, Adams R, Carnethon M, De Simone G, Ferguson TB, Flegal K, Ford E, Furie K, Go A, Greenlund K, et al; American Heart Association Statistics Committee and Stroke Statistics Subcommittee: Heart disease and stroke statistics - 2009 update: a report from the American Heart Association Statistics Committee and Stroke Statistics Subcommittee. Circulation 119: 480-486, 2009.

2. Young RR: Spasticity: a review. Neurology 44 (Suppl 9): S12-S20, 1994

3. Qin Z: Clinical Neurophysiology. Shanghai Scientific and Technical Publishers, Shanghai, pp109-155, 1984.

4. Zhao HY: Master Translator. Harrison's Principles of Internal Medicine. 12th edition. People's Medical Publishing House, Beijing, pp207-210, 1994.

5. Doraisamy P: The management of spasticity - a review of options available in rehabilitation. Ann Acad Med Singapore 21: 807-812, 1992.

6. Brin MF: Botulinum toxin: chemistry, pharmacology, toxicity, and immunology. Muscle Nerve (Suppl) 6: S146-S168, 1997.

7. Brashear A, Gordon MF, Elovic E, Kassicieh VD, Marciniak C, Do M, Lee CH, Jenkins S and Turkel C; Botox Post-Stroke Spasticity Study Group: Intramuscular injection of botulinum toxin for the treatment of wrist and finger spasticity after a stroke. N Engl J Med 347: 395-400, 2002.

8. Li TS: Manual of Botulinum Toxin Therapy. Peking University Medical Press, Beijing, pp10-11, 2012.

9. Scott AB, Rosenbaum A and Collins CC: Pharmacologic weakening of extraocular muscles. Invest Ophthalmol 12: 924-927, 1973.

10. Scott AB: Botulinum toxin injection into extraocular muscles as an alternative to strabismus surgery. Ophthalmology 87: 1044-1049, 1980.

11. Wu CL, Wang LP and Sun XF: Clinical observation of treating limb spasticity after stroke by electromsyogramguided botulinum toxin A. China Pharmaceuticals 17: 50-51, 2008 (In Chinese).

12. Sheean GL: Botulinum treatment of spasticity: why is it so difficult to show a functional benefit? Curr Opin Neurol 14: 771-776, 2001.

13. Lan Y, Dou ZL, Hu XQ, Xu GQ and Qiu WH: Clinical study of botulinum toxin type A injection in the treament of upper limb spasticity in stroke patients. Chinese J Physical Med Rehabil 29: 754-757, 2007 (In Chinese).

14. Schroeder AS, Berweck S, Lee SH and Heinen F: Botulinum toxin treatment of children with cerebral palsy - a short review of different injection techniques. Neurotox Res 9: 189-196, 2006.

15. Dou ZL and Ou HN: Spasticity Botulinum Toxin Type A Positioning Injection Techniques. People's Medical Publishing House, 2012.

16. Yang EJ, Rha DW, Yoo JK and Park ES: Accuracy of manual needle placement for gastrocnemius muscle in children with cerebral palsy checked against ultrasonography. Arch Phys Med Rehabil 90: 741-744, 2009.

17. Zuo Z, Ou H, Shen J, Yuan X and Lan Y: The clinical effect of ultrasound guided botulinum toxin type A (BTXA) injection in treating muscles spasticity following stroke (5 cases report). Chinese J Rehabil Med 23: 219-221, 2008 (In Chinese). 
18. Yang Y, Zhang Z, Wang P, Du J, Qu Y, Zhu L, Song W and Wang M: Comparison between ultrasound combined with electrical stimulation-guidance and electrical stimulation-directing BTX-A injection in poststroke patients with spasticity. Chinese J Rehabil Med 23: 903-905, 2008 (In Chinese).

19. Takahashi M, Miyamura H, Eguchi S and Homma S: The effect of bupivacaine hydrochloride on skeletal muscle fiber type transformation by low frequency electrical stimulation. Neurosci Lett 155: 191-194, 1993.

20. Dupont Salter AC, Richmond FJ and Loeb GE: Prevention of muscle disuse atrophy by low-frequency electrical stimulation in rats. IEEE Trans Neural Syst Rehabil Eng 11: 218-226, 2003.

21. Li W: Diagnostic points for various cerebrovascular diseases. Chinese J Neurol 29: 379-380, 1996 (In Chinese).

22. Chinese Association Of Rehabilitation Medicine: China guide for botulinum toxin to treat adult limb myospasm (2010). Chinese J Rehabil Med 25: 595-620, 2010 (In Chinese).

23. Bohannon RW and Smith MB: Interrater reliability of a modified Ashworth scale of muscle spasticity. Phys Ther 67: 206-207, 1987.

24. Tiebin Y and Zulin D: Practice of Paralysis Rehabilitation. People's Medical Publishing House, 1999.

25. Carr JH, Shepherd RB, Nordholm L and Lynne D: Investigation of a new motor assessment scale for stroke patients. Phys Ther 65: $175-180,1985$

26. Maia MO, Dantas CG, Xavier Filho L, Cândido EA and Gomes MZ: The effect of Alpinia zerumbet essential oil on post-stroke muscle spasticity. Basic Clin Pharmacol Toxicol 118: 58-62, 2016.

27. Guo M and Yu S: Rehabilitation of spasticity secondary to stroke in hemiplegic patients. Chinese J Rehabil Med 15: 287-288, 2000 (In Chinese).

28. Das TK and Park DM: Effect of treatment with botulinum toxin on spasticity. Postgrad Med J 65: 208-210, 1989.

29. Frueh BR, Felt DP, Wojno TH and Musch DC: Treatment of blepharospasm with botulinum toxin. A preliminary report. Arch Ophthalmol 102: 1464-1468, 1984.

30. Childers MK, Brashear A, Jozefczyk P, Reding M, Alexander D, Good D, Walcott JM, Jenkins SW, Turkel C and Molloy PT: Dose-dependent response to intramuscular botulinum toxin type A for upper-limb spasticity in patients after a stroke. Arch Phys Med Rehabil 85: 1063-1069, 2004.

31. Esquenazi A, Mayer N and Garreta R: Influence of botulinum toxin type A treatment of elbow flexor spasticity on hemiparetic gait. Am J Phys Med Rehabil 87: 305-310, quiz 311, 329, 2008.
32. Cousins E, Ward AB, Roffe C, Rimington LD and Pandyan AD: Quantitative measurement of poststroke spasticity and response to treatment with botulinum toxin: A 2-patient case report. Phys Ther 89: 688-697, 2009.

33. Baricich A, Carda S, Bertoni M, Maderna L and Cisari C: A single-blinded, randomized pilot study of botulinum toxin type A combined with non-pharmacological treatment for spastic foot. J Rehabil Med 40: 870-872, 2008.

34. Chin TY, Nattrass GR, Selber P and Graham HK: Accuracy of intramuscular injection of botulinum toxin $\mathrm{A}$ in juvenile cerebral palsy: a comparison between manual needle placement and placement guided by electrical stimulation. J Pediatr Orthop 25: 286-291, 2005

35. Brashear A: Botulinum toxin type A in the treatment of patients with cervical dystonia. Biologics 3: 1-7, 2009.

36. Matarasso SL: Update on the aesthetic uses of botulinum-A neurotoxin in facial rejuvenation. Curr Probl Dermatol 13: 46-53, 2001.

37. Lebeda FJ and Olson MA: Secondary structural predictions for the clostridial neurotoxins. Proteins 20: 293-300, 1994.

38. Jankovic J: Botulinum toxin in clinical practice. J Neurol Neurosurg Psychiatry 75: 951-957, 2004.

39. Hesse S, Reiter F, Konrad M and Jahnke MT: Botulinum toxin type $\mathrm{A}$ and short-term electrical stimulation in the treatment of upper limb flexor spasticity after stroke: a randomized, double-blind, placebo-controlled trial. Clin Rehabil 12: 381-388, 1998.

40. Pullman SL, Greene P, Fahn S and Pedersen SF: Approach to the treatment of limb disorders with botulinum toxin A. Experience with 187 patients. Arch Neurol 53: 617-624, 1996.

41. Felsenthal G: Pharmacology of phenol in peripheral nerve blocks: a review. Arch Phys Med Rehabil 55: 13-16, 1974.

42. Frasson E, Priori A, Ruzzante B, Didonè $G$ and Bertolasi L: Nerve stimulation boosts botulinum toxin action in spasticity. Mov Disord 20: 624-629, 2005

43. Guanghui Z, Keliang X, Qing Z,Zhengyu Z and Zhibin H: Effect of facilitation techniques combined with acupuncture in patients with hemiplegia after stroke. Chinese Rehabil Practice 9: 148, 2003 (In Chinese).

44. Tong Z: Dysfunction and Rehabilitation after Stroke. Scientific and Technical Documentation Press, Beijing, p323, 2006. 